\title{
Sediment provenance and evolution of the East Asian winter monsoon since 700 ka recorded by major elements in the West Philippine Sea
}

\author{
XU ZhaoKai ${ }^{1}$, LI TieGang ${ }^{1 *}$, YU XinKe ${ }^{1}$, LI AnChun ${ }^{1}$, TANG Zheng ${ }^{2}$, CHOI JinYong ${ }^{3} \&$ \\ NAN QingYun ${ }^{1}$ \\ ${ }^{1}$ Key Laboratory of Marine Geology and Environment, Institute of Oceanology, Chinese Academy of Sciences, Qingdao 266071, China; \\ ${ }^{2}$ Key Laboratory of Marine Hydrocarbon Resources and Environmental Geology, Qingdao Institute of Marine Geology, Ministry of Land and \\ Resources of China, Qingdao 266071, China; \\ ${ }^{3}$ Department of Oceanography, Kunsan National University, Kunsan 573-701, Korea
}

Received May 22, 2012; accepted September 28, 2012; published online November 22, 2012

\begin{abstract}
To synthetically realize the character of major-element compositions as well as its significance for provenance and paleoenvironment recorded in core sediments of the West Philippine Sea over the last $700 \mathrm{ka}$, grain size and major elements of 221 bulk sediments, together with major-element compositions in the detrital phase of 16 typical samples, in core MD06-3047 collected from the Benham Rise were analyzed. Both discrimination plot and R-mode factor analysis indicate that vertical changes of major elements are mainly controlled by the sedimentation of nearby volcanic matter and the eolian dust input, whereas influences from marine biologic deposition and hydrothermal activity are minor. In particular, $\mathrm{Al}_{2} \mathrm{O}_{3}$ and $\mathrm{K}_{2} \mathrm{O}$ are representative of an eolian dust factor. The variation in the eolian dust factor score is characterized by the obviously glacial-interglacial periodicity and can be well compared with the paleotemperature record of the Antarctic ice core and the evolution of the East Asian winter monsoon (EAWM) recorded in the Chinese loess sequence, and then offers a new proxy for the evolution history of eolian dust input into the study area that is controlled by the EAWM intensity and aridity in the continental source regions of atmospheric dust.
\end{abstract}

major elements, provenance, eolian dust, East Asian winter monsoon, West Philippine Sea

Citation: $\quad \mathrm{Xu} \mathrm{Z} \mathrm{K,} \mathrm{Li} \mathrm{T} \mathrm{G,} \mathrm{Yu} \mathrm{X} \mathrm{K,} \mathrm{et} \mathrm{al.} \mathrm{Sediment} \mathrm{provenance} \mathrm{and} \mathrm{evolution} \mathrm{of} \mathrm{the} \mathrm{East} \mathrm{Asian} \mathrm{winter} \mathrm{monsoon} \mathrm{since} 700$ ka recorded by major elements in the West Philippine Sea. Chin Sci Bull, 2013, 58: 1044-1052, doi: 10.1007/s11434-012-5538-8

The Philippine Sea is a large deep-sea in the West Pacific where geologic setting is complex. The Philippine Plate is located between the Eurasia Plate and the Pacific Plate and has important influence on the southeast Chinese continent and Philippines. Besides, the globally famous warm current (i.e. the Kuroshio Current) also originates from the West Philippine Sea (WPS). The geologic significance of the Philippine Sea began to be recognized by global scientists in 1970s. Since then, six cruises of DSDP and ODP have been carried out on this sea. However, besides the past researches of DSDP and ODP with generally large time scale (i.e. tectonic scale), synthetically geochemical work on core

*Corresponding author (email: tgli@qdio.ac.cn) sediments of the WPS with relatively high time resolution is still scarce $[1,2]$.

The East Asian monsoon is one of the major components of global climate system, which is driven by differential heating between the West Pacific Warm Pool and the Asian continent, and is characterized by seasonal switch in wind direction, precipitation, and runoff [3]. During winter months, low temperatures over the Asian continent induce the development of a high-pressure cell over the North Asia. This produces cold and dry winds blowing from the central Asia to the West Pacific [3,4]. Over the last several decades, many scientists have attempted to discuss the EAWM evolution and aridity of the inner Asian continent recorded by the Chinese loess sequence as well as eolian dust fraction in 
marine sediments of the South China Sea, North Pacific, and even tropical Pacific [5-8]. Among them, majorelement indices are still rare. As to the Philippine Sea, although the eolian dust input from the inner Asian continent has been deduced to influence sediment compositions and sea surface nutrients therein based on different indices including clay mineralogy, geochemistry, and pollen [1,2,9-11], whereas the lack of high resolution chronology in the previous studies seriously restrict their progresses. Particularly, the evolution history of eolian dust input into the source area of the Kuroshio Current during the late Quaternary still remains unresolved at present.

Previous researches demonstrated that major-element compositions, chemical phase of element existence, and $\mathrm{R}$-mode factor analysis were useful research aspects in reflecting the origin, provenance, and transport path of marine sediments [1,12-15]. Based on synthetic analyses of major-element contents of 221 bulk sediments and detrital phase of 16 typical samples, combining with our previous work on surface sediments of the East Philippine Sea (EPS) $[9,12,15]$, the present study aims to reveal the general character of major elements in core samples of the WPS, and then the better understanding on sediment provenance as well as its paleoenvironmental significance.

\section{Materials and methods}

\subsection{Geological setting and samples}

A Calypso core (MD06-3047), $8.9 \mathrm{~m}$ long, was taken from the Benham Rise, east off Luzon Island $\left(17^{\circ} 00.44^{\prime} \mathrm{N}\right.$, $\left.124^{\circ} 47.93^{\prime} \mathrm{E}\right)$ at a water depth of $2510 \mathrm{~m}$ during the joint Chinese-French Marco Polo 2 Cruise in 2006. For the obstruction effect of the Kuroshio Current (from south to north) and scattered deep trenches (rifts) nearby, adding the long distance of the study area away from continents and large islands, therefore very few riverine materials from the Chinese continent and Japan can be carried to the study area $[1,2,9,10]$.

Core MD06-3047 is composed of yellowish silty mud with obvious black volcanic ash layers. It contains continuous sedimentation with no obvious gap or abrupt interruption. For the study core is located above the lysocline (3400 $\mathrm{m})$ therein, carbonate is well preserved in the study core [16].

\subsection{Methods}

A total of 357 samples were dried at $50^{\circ} \mathrm{C}$. After drying, each sample was treated with $5 \%$ hydrogen peroxide to oxidize organic matter and then washed through a $63 \mu \mathrm{m}$ sieve to recover the benthic foraminifera tests. Oxygen isotopes of foraminifera tests were measured on a GV IsoPrime mass spectrometer in the Key Laboratory of Marine Geology and Environment, Institute of Oceanography, Chinese Academy of Sciences (KLMGE, IO, CAS). Analyses were carried out on samples containing 3-8 specimens of the benthic foraminifer $C$. wuellerstorfi $(>300 \mu \mathrm{m})$. The analytical precision was better than $\pm 0.08 \%$ o for $\delta^{18} \mathrm{O}$. Calibration to PDB was performed using NBS19 standard.

Besides, 221 samples generally with $4 \mathrm{~cm}$ intervals were oven dried at $50^{\circ} \mathrm{C}$ and then powdered to below 200 meshes. Each powdered sample was completely digested and analyzed for contents of major elements, typical minor elements (V and $\mathrm{Cd}$ ), and rare earth elements (REE) using an Inductively Coupled Plasma Optical Emission Spectrometer (ICP-OES) and an ICP-Mass Spectrometer (ICP-MS) in the Central Laboratory, Institute of Geophysical and Geochemical Exploration, Chinese Academy of Geological Sciences (CL, IGGE, CAGS). The analytical precision and accuracy were monitored by national geostandard GSD9. Differences between the determined and certified values were less than $4 \%$.

Sequential extraction on chemical phase of element existence was made with the method simplified from $\mathrm{Xu}$ et al. $[9,12]$. Here, the bulk compositions were divided into the detrital phase and non-detrital phase (including pore water, adsorption, carbonate, ferromanganese oxide, and organic phase mentioned by $\mathrm{Xu}$ et al. [9,12]) with hydrogenetic/biogenic origin using different reagents (deionized water, $\mathrm{NaAc}, \mathrm{HAc}, \mathrm{NH}_{2} \cdot \mathrm{OH} \cdot \mathrm{HCl}$, and $\mathrm{HNO}_{3} \cdot \mathrm{H}_{2} \mathrm{O}_{2}$ ) [9, 12]. The recovery rate for main major elements with detrital origin (e.g. $\mathrm{Fe}, \mathrm{Mg}$, and $\mathrm{K}$ ) in the study sediments was generally within $95 \%-105 \%$. Compositions of major elements in the detrital phase of 16 samples collected from typically glacial-interglacial periods were measured with an ICP-OES in the CL, IGGE, CAGS with precision better than $3 \%$.

Furthermore, we carried out grain size measurement on all samples used for major-element analysis, except a sample used up. Each sample was pretreated to remove organic matter and carbonate. The analysis was performed on a $\mathrm{Ci}$ las Particle Size Analyzer (Cilas 940L) in the KLMGE, IO, CAS. The used apparatus accounts for grains in the 0.5 to $2000 \mu \mathrm{m}$ range with reproducibility better than $2 \%$.

\section{Results}

The applied age model in this study was obtained by comparing our $\delta^{18} \mathrm{O}$ curve for the benthic foraminifer $C$. wuellerstorf $i$ with the standard LR0 $4 \delta^{18} \mathrm{O}$ stack (Figure 1) [17]. The last appearance datum of G. ruber (pink) appeared at the depth of $160 \mathrm{~cm}$ with a known age of $120 \mathrm{ka}$ in the West Pacific was also used [18]. Therefore, the study core spans Marine Isotope Stages (MIS) 1-17, thus recording the paleoceanographic history of the last $696 \mathrm{ka}$ with an average time resolution of $0.78 \mathrm{ka} / \mathrm{cm}$. Besides, the validity of this chronology has also been confirmed by identification results on calcareous nannofossil bioevents [16].

A summary of compositions of major elements of the 


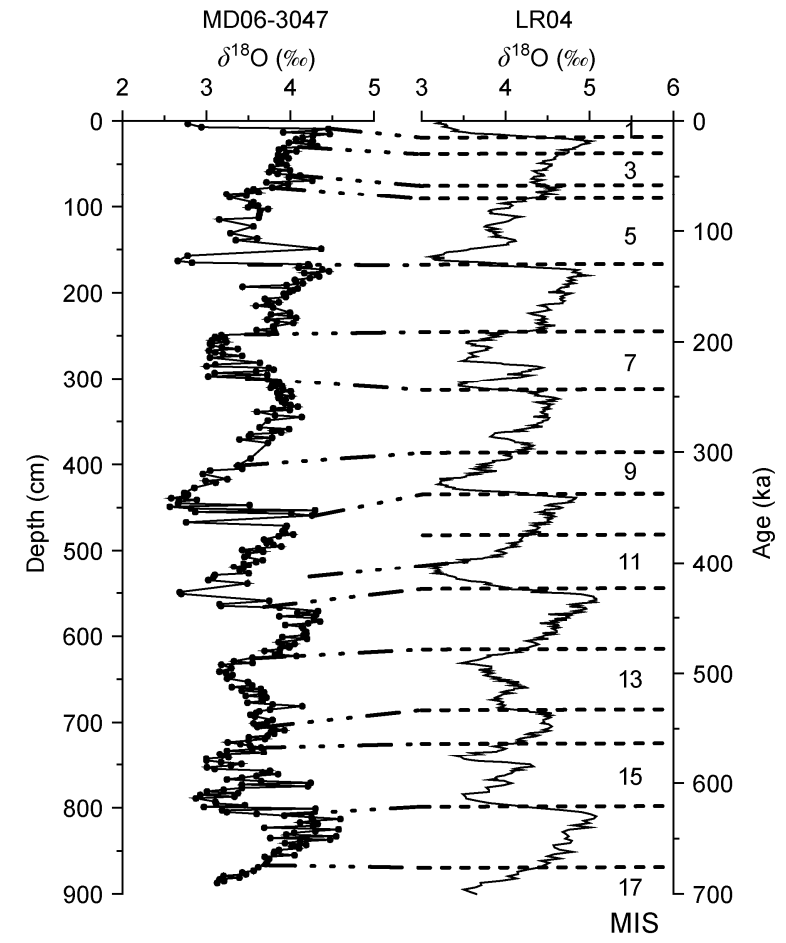

Figure 1 Comparison between our $\delta^{18} \mathrm{O}$ curve with the LR04 $\delta^{18} \mathrm{O}$ stack [17].

present core sediments and related materials is listed in Table 1 . Contents of $\mathrm{Na}_{2} \mathrm{O}, \mathrm{MnO}$, and $\mathrm{P}_{2} \mathrm{O}_{5}$ fluctuate widely without obvious change trend with depth in the study core. Whereas other major elements of these samples are all characterized by clear glacial-interglacial periodicity (Figure 2). Under a condition of $80 \%$ cumulated variance in R-mode factor analysis, four factors, including F1, F2, F3, and $\mathrm{F} 4$, which are characterized by different associations of major elements were obtained using SPSS11.0 software (Table 2). Varimax rotation was applied to get typical factors under the precondition of eigenvalue higher than 1 . The cumulated variance of these four factors together accounts for $83.95 \%$ of the total variance in the sediment properties (Table 2), indicating the validity of the present analysis $[14,15]$. From analysis results of chemical phase of element existence for 16 typical samples, we can see that most major elements ( $\mathrm{Al}, \mathrm{Fe}, \mathrm{Mg}, \mathrm{K}$, and $\mathrm{P}$ ) concentrate in the detrital phase, with the lowest average value of $76.1 \%$; while $\mathrm{Mn}$ and $\mathrm{Ca}$ are enriched in the non-detrital phase with hydrogenetic/biogenic origin, with very low average values of $36.0 \%$ and $14.9 \%$ in the detrital phase, respectively (Table 3).

\section{Discussion}

\subsection{Major-element compositions and typical element ratios}

Compared with major-element compositions of nearby sediments in the EPS and global reference materials including UCC and PAAS, those of core MD06-3047 sediments show deep-sea sedimentation character (Table 1) [15]. From studies of major-element compositions of core sediments in the WPS and surface sediments in the EPS, nearby volcanic matter and eolian dust from the inner Asian continent have been deduced to be two main provenances of them $[1,12,15]$. From Table 1, we can also see that contents of most major elements in core MD06-3047 sediments are dominantly located between those of nearby volcanic matter and eolian dust.

Al element in marine sediments mostly exists in aluminosilicate minerals with detrital origin and is relatively stable in the sedimentation process, but is not involved in biological medium in general. Analysis results of chemical phase of element existence for 16 typical samples also indicate that $\mathrm{Al}$ mainly concentrates in the detrital phase with an average value of $88.2 \%$ (Table 3 ). Hence, the element normalization to $\mathrm{Al}$ can be used to study the material source and elemental change in marine environment, compensating the influence of mineralogy and grain size $[15,25,26]$. In fact, poor correlations are presented between $\mathrm{Mz}$ and contents

Table 1 Comparison on compositions of major elements between core MD06-3047 sediments and related materials (\%)

\begin{tabular}{|c|c|c|c|c|c|c|c|c|c|}
\hline \multirow{2}{*}{ Element } & \multicolumn{2}{|c|}{ MD06-3047 } & \multirow{2}{*}{ EPS sediment [15] } & \multirow{2}{*}{$\mathrm{UCC}^{\mathrm{b})}[19]$} & \multirow{2}{*}{ PAAS $^{c)}[19]$} & \multicolumn{3}{|c|}{ Nearby volcanic matter [20-22] } & \multirow{2}{*}{$\begin{array}{c}\text { Eolian dust }[23,24] \\
\text { Chinese loess }\end{array}$} \\
\hline & Average & $\mathrm{SD}^{\mathrm{a})}$ & & & & Luzon & $\mathrm{KPR}^{\mathrm{d})}$ & $\mathrm{WMR}^{\mathrm{e})}$ & \\
\hline $\mathrm{Al}_{2} \mathrm{O}_{3}$ & 14.06 & 0.912 & 15.64 & 15.20 & 18.90 & 18.25 & 14.43 & 17.80 & 11.88 \\
\hline $\mathrm{TFe}_{2} \mathrm{O}_{3}$ & 5.99 & 0.631 & 9.36 & 5.00 & 7.22 & 8.55 & 13.33 & 9.43 & 4.18 \\
\hline $\mathrm{MgO}$ & 2.84 & 0.318 & 3.58 & 2.20 & 2.20 & 4.61 & 6.23 & 4.86 & 2.36 \\
\hline $\mathrm{CaO}$ & 11.75 & 2.335 & 2.47 & 4.20 & 1.30 & 8.68 & 9.66 & 10.26 & 7.80 \\
\hline $\mathrm{Na}_{2} \mathrm{O}$ & 3.37 & 0.368 & 4.24 & 3.90 & 1.20 & 3.42 & 3.13 & 3.08 & 1.77 \\
\hline $\mathrm{K}_{2} \mathrm{O}$ & 1.54 & 0.164 & 2.43 & 3.40 & 3.70 & 1.06 & 0.71 & 1.00 & 2.25 \\
\hline $\mathrm{TiO}_{2}$ & 0.59 & 0.061 & 0.78 & 0.50 & 1.00 & 0.76 & 1.18 & 0.67 & 0.60 \\
\hline $\mathrm{MnO}$ & 0.20 & 0.109 & 1.09 & 0.08 & 0.11 & 0.17 & 0.21 & 0.17 & 0.06 \\
\hline $\mathrm{P}_{2} \mathrm{O}_{5}$ & 0.03 & 0.003 & 0.29 & - & 0.16 & 0.28 & 0.12 & 0.16 & 0.15 \\
\hline
\end{tabular}

a) SD: Standard deviation; b) UCC: Upper Continental Crust; c) PAAS: Post-Archaean Australian Shale; d) KPR: Kyushu-Palau Ridge; e) WMR: West Mariana Ridge. 

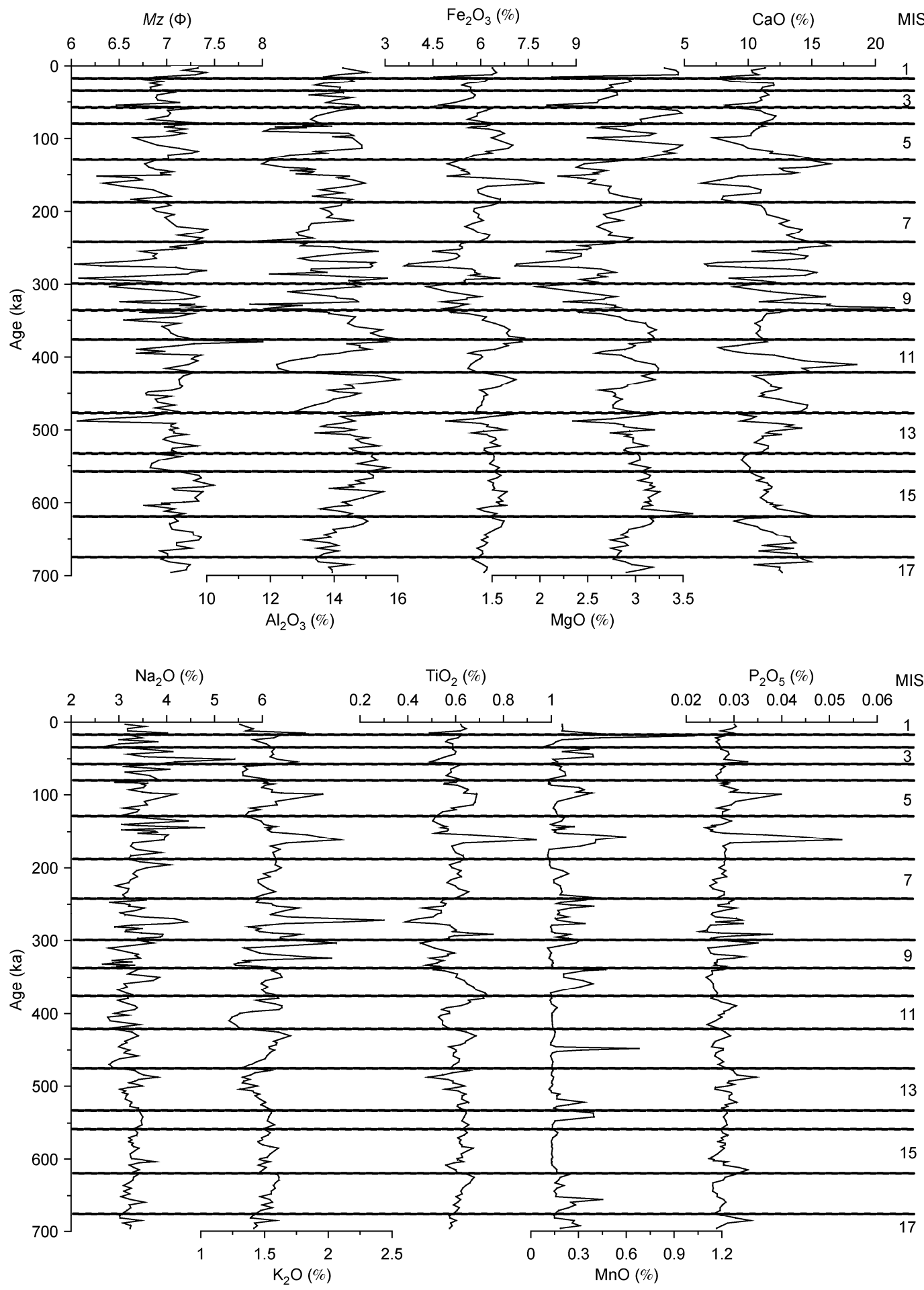

Figure 2 Depth profiles of mean grain size (Mz) and major elements of core MD06-3047 sediments.

Table 2 Loads of major elements and variance for each factor in core MD06-3047 sediments

\begin{tabular}{ccccccccccc}
\hline Factor & $\mathrm{Al}_{2} \mathrm{O}_{3}$ & \multicolumn{1}{c}{$\mathrm{TFe}_{2} \mathrm{O}_{3}$} & $\mathrm{MgO}$ & $\mathrm{CaO}$ & $\mathrm{Na}_{2} \mathrm{O}$ & $\mathrm{K}_{2} \mathrm{O}$ & $\mathrm{TiO}_{2}$ & $\mathrm{MnO}$ & $\mathrm{P}_{2} \mathrm{O}_{5}$ & Variance $(\%)$ \\
\hline $\mathrm{F} 1$ & 0.30 & 0.97 & 0.85 & -0.13 & -0.27 & -0.34 & 0.89 & -0.02 & 0.20 & 34.84 \\
$\mathrm{~F} 2$ & 0.88 & 0.16 & -0.11 & -0.81 & 0.28 & 0.69 & 0.23 & 0.13 & 0.14 & 30.81 \\
$\mathrm{~F} 3$ & 0.02 & -0.02 & -0.23 & -0.33 & 0.73 & 0.46 & 0.16 & 0.11 & 0.80 & 10.45 \\
$\mathrm{~F} 4$ & 0.03 & 0.02 & -0.15 & -0.12 & -0.10 & 0.17 & 0.14 & 0.95 & 0.29 & 7.85 \\
\hline
\end{tabular}


Table 3 Relative percents of major elements in the detrital phase of 16 typical sediments in core MD06-3047 (\%)

\begin{tabular}{lccccccccc}
\hline \multicolumn{1}{c}{ Percent } & $\mathrm{Al}_{2} \mathrm{O}_{3}$ & $\mathrm{TFe}_{2} \mathrm{O}_{3}$ & $\mathrm{MgO}$ & $\mathrm{CaO}$ & $\mathrm{Na}_{2} \mathrm{O}$ & $\mathrm{K}_{2} \mathrm{O}$ & $\mathrm{MnO}^{2}$ & $\mathrm{P}_{2} \mathrm{O}_{5}$ \\
\hline Minimum & 80.3 & 95.2 & 82.7 & 8.2 & 37.0 & 82.1 & 8.4 & 59.4 \\
Maximum & 99.5 & 106.3 & 95.4 & 26.6 & 68.1 & 92.1 & 68.1 & 86.5 \\
Average & 88.2 & 101.3 & 87.6 & 14.9 & 48.8 & 86.6 & 36.0 & 76.1 \\
$\mathrm{SD}$ & 4.46 & 3.04 & 3.87 & 5.60 & 9.04 & 2.62 & 19.27 & 8.52 \\
\hline
\end{tabular}

of nine major elements of core MD06-3047 sediments (Figure 2), excluding grain size as an important factor for controlling major-element compositions of the study samples. Combined metal ratios (e.g. Fe/Al ratio and V/Al ratio) have been successfully used to identify the origin of marine sediments in the West Pacific [15,25,26]. Using possible source materials, core MD06-3047 sediments can be examined based on these two variables [26]. As shown in Figure 3 , most of the study sediments are located between Luzon volcanic matter and eolian dust. Meanwhile, the average $\mathrm{Fe} / \mathrm{Al}$ ratio of the study samples $(0.57)$ is also in the range of eolian dust (average 0.44 ) and nearby volcanic source (Luzon, average 0.62) [20,21,23,24]. However, the possibility of biologic matter as one of the main sediment provenances of the study major elements could be preliminarily excluded, as approved by its obviously different average $\mathrm{Fe} / \mathrm{Al}$ ratio of 1.56 from the present work [25]. Besides, analysis results of chemical phase of element existence also indicate that the non-detrital phase (e.g. carbonate and organic matter) is only contributing to limited major elements including $\mathrm{Mn}$ and $\mathrm{Ca}$ (Table 3).

REE have been well accepted as reliable provenance tracers because they are large terrigenous components reflecting their sources in the Philippine Sea sediments.

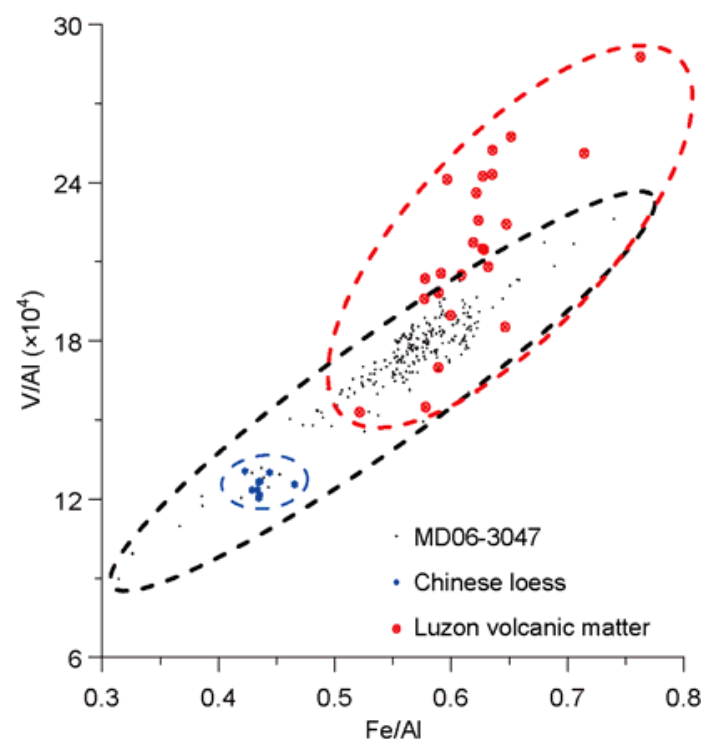

Figure 3 Discrimination plot showing the provenance of core MD063047 sediments based on Fe/Al vs. V/Al. The reference data of Luzon volcanic matter and Chinese loess were cited from [21-24].
However, biologic materials (e.g. carbonate) only have minor contributions to bulk REE compositions therein $[9,12]$. The PAAS-normalized REE patterns of core MD06-3047 sediments clearly show characteristics of light REE (LREE; from La to Eu) depletion, heavy REE (HREE; From Gd to Y) enrichment, and positive Eu anomaly (Figure 4). Furthermore, the study sediments have very similar character of LREE depletion to typical Luzon volcanic matter with comparable age range (Figure 4), indicating that nearby volcanic matter should be the main provenance of the study sediments [9,12]. Another possible source, i.e. Chinese loess, is characterized by generally flat REE pattern and a little similar HREE contents to the study core, indicating its less REE contribution to the study samples (Figure 4). Among the possible provenances of the Philippine Sea sediments, only nearby basaltic rocks are characterized by positive Eu anomaly, whereas Chinese loess is neutral. Therefore, the positive Eu anomaly character in the present sediments should be interpreted as the influence from nearby volcanic input again $[9,12]$. In particular, REE can be used for quantitatively estimating the influence of eolian dust from the Asian continent as well as the contribution of locally basaltic detrital matter to pelagic sediment in the North Pacific [27]. Accordingly, eolian dust proportion of the top sample of core MD06-3047 is estimated to be $27.5 \%$, and then its mass accumulation rate (MAR) is calculated to be $143.2 \mathrm{mg} \mathrm{cm}^{-2} \mathrm{ka}^{-1}$ (Xu, unpublished data). Based on strontium isotopic compositions of a nearby surface sediment to the study core (NGC8 at $16^{\circ} 19.76^{\prime} \mathrm{N}, 137^{\circ} 59.30^{\prime} \mathrm{E}$ ) and the related formula for provenance end-member calculation [2,28], its eolian dust content is calculated to be $26.4 \%$, which is very consistent with the present study. As to eolian dust MAR of the top sample of core MD06-3047, it is located within the range of MAR for mineral aerosol in the study sea (100-1000 $\mathrm{mg} \mathrm{cm}^{-2} \mathrm{ka}^{-1}$ ), too [29].

In sum, the above discussion confirms that nearby volcanic matter and eolian dust are two dominant provenance end-members of core MD06-3047 sediments, which is also consistent with our pervious conclusions got from studying on surface sediments in the EPS $[9,12,15]$. Among these two end-members, volcanic matter on Luzon with location in the west of the study area might be transported here through riverine input and/or oceanic current [30,31], whereas that on KPR and MR located in the east could be carried to the study area by the westward-flowing current (North Equator Current) [9]. For example, Luzon, the largest 


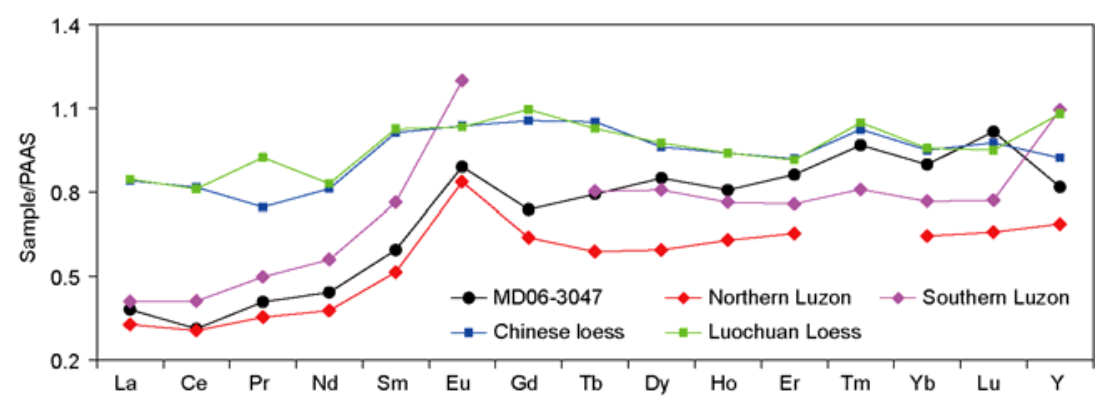

Figure 4 Comparison of the PAAS-normalized REE patterns of core MD06-3047 sediments with volcanic matter of northern Luzon [22] and southern Luzon [21] as well as Chinese loess [23,24].

island of Philippines, is an intermediate-basaltic volcanic and tectonically active island characterized by high relief, heavy rainfall (annual total precipitation of 1900-2100 mm), and warm temperature $\left(23-34^{\circ} \mathrm{C}\right.$; http://www.worldweather. org). Therefore, strongly chemical weathering process of volcanic matter should exist in Luzon, such as a presently moderate-intensive chemical weathering degree of clay size $(<2 \mu \mathrm{m})$ sediments in its rivers [32]. Thus produced fine volcanic matter might be carried to the study area in suspended form [31]. As to eolian dust sourced from the aridity areas of the Asian continent, it could be transported here by the EAWM [9-11].

\subsection{R-mode factor analysis}

Synthesizing the above characteristics of major elements and source discrimination results, the study sediments are deduced to mainly result from nearby volcanic matter and eolian dust that both have detrital origin. To further validate our deduction on sediment provenance, R-mode factor analysis of major elements in 221 samples was performed.

$\mathrm{F} 1$, the largest one among four extracted factors, accounts for $34.84 \%$ of the total variance, indicating its most important contribution to major-element compositions of the study core sediments. It is composed of $\mathrm{TFe}_{2} \mathrm{O}_{3}, \mathrm{MgO}$, and $\mathrm{TiO}_{2}$ with all positive loads. $\mathrm{Fe}, \mathrm{Mg}$, and $\mathrm{Ti}$ are relatively stable in the sedimentation process and concentrated in volcanic matter (e.g. basalt on Luzon, KPR, and WMR) [20-22], as approved by their enrichment in the detrital phase of core MD06-3047 sediments with average values all higher than $87.6 \%$ (Table 3). Combining our above analyses in the present study and previous research results on surface sediments of the EPS [15], the association reflected by F1 is of volcanic nature (i.e. F1 is a volcanic factor). This can be further confirmed by the obvious enrichment of these elements in nearby volcanic matter than those in core MD063047 sediments and another main provenance end-member, namely eolian dust (Table 1).

F2, the second largest one among four factors, accounts for $30.81 \%$ of the total variance, and is characterized by the assemblage of $\mathrm{Al}_{2} \mathrm{O}_{3}$ and $\mathrm{K}_{2} \mathrm{O}$ that both have positive loads. They are also enriched in the detrital phase, with average values of $88.2 \%$ and $86.6 \%$, respectively. In fine marine sediments, clay minerals such as illite, chlorite, and muscovite are usually abundant, leading to high contents of $\mathrm{Al}_{2} \mathrm{O}_{3}$ and $\mathrm{K}_{2} \mathrm{O}$ [15]. Particularly, previously chemical analysis on illite collected from nearby core sediments in the WPS indicated its enrichment on $\mathrm{Al}_{2} \mathrm{O}_{3}$ (average 36.36\%) and $\mathrm{K}_{2} \mathrm{O}$ (average 5.97\%) [30]. For eolian dust from the Asian continent is the main source of illite in the Philippine Sea [10,30], and then F2 should be an eolian dust factor. Besides, downcore changes of $\mathrm{F} 2$ score, $\mathrm{Al}_{2} \mathrm{O}_{3}$ content, and $\mathrm{K}_{2} \mathrm{O}$ content are positively correlated with that of eolian dust proportion estimated from REE data, with correlation coefficients all higher than 0.49 ( $\mathrm{Xu}$, unpublished data). As to surface sediments in the EPS, similar factor (i.e. F2) only accounts for $14.79 \%$ of the total variance, much lower than the present study, indicating the higher contribution of eolian dust to the study area than that to the EPS. This is consistent with the farther distance of the EPS from the continental source regions of atmospheric dust and then weaker influence from eolian dust $[5,9,10,30]$. Notably, F2 includes $\mathrm{CaO}$ with negative load, indicating the possible dilution effect of carbonate [15].

$\mathrm{F} 3$, the third largest one among four factors, accounts for $10.45 \%$ of the total variance, and is characterized by the association of $\mathrm{Na}_{2} \mathrm{O}$ and $\mathrm{P}_{2} \mathrm{O}_{5}$ with both positive loads. According to previous research results on related marine sediments, a strong $\mathrm{Na}_{2} \mathrm{O}$ signal has widely been used as an indicator of volcanic event, while the latter might be offered by biologic organism $[13,15]$. Therefore, this factor should reflect co-influences from nearby volcanic action and biologic effect.

$\mathrm{F} 4$, the smallest one among four extracted factors, only accounts for $7.85 \%$ of the total variance. It is characterized by $\mathrm{MnO}$ with positive load. $\mathrm{Mn}$ has been deduced to be closely associated with hydrothermal activity [13], or a typical autogenic element resulting from early diagenesis $[14,33]$. From the generally small fluctuation range of $\mathrm{MnO}$ content as well as the disappearance of obvious enrichment-depletion interface in the study core (Figure 2), adding its dominant occurrence in the non-detrital phase (average $64.0 \%$ ) with hydrogenetic origin (Table 3 ), we can conclude that F4 characterized by $\mathrm{MnO}$ is a hydrothermal factor. Poor 
correlations between $\mathrm{Mn}$ and other redox sensitive indices (e.g. $\mathrm{Fe}, \mathrm{Cd}$, and $\mathrm{Ce}$ anomaly) $[9,12,33]$, with very low correlation coefficients of $0.02,0.04$, and 0.17 , further exclude $\mathrm{Mn}$ as a redox sensitive element in the study core sediments.

Therefore, major-element compositions of core MD063047 sediments are deduced to mainly derive from nearby volcanic matter and eolian dust with both detrital origin. However, influences from biologic effect and hydrothermal activity are minor.

\subsection{Paleoenvironmental implication of the eolian dust factor}

One typical effect of the evolution of the East Asian monsoon is physical weathering in the continental source regions, and thus the supply of eolian dust to the seabed. In detail, the EAWM enhancement corresponds to strengthened aridity and physical weathering in the continental source regions of atmospheric dust, leading to higher proportion of eolian dust in marine sediments of the sink areas (e.g. North Pacific and marginal seas of the West Pacific), and vice versa. Recently, R-mode factor analyses of ma- jor-element compositions have been successfully used to probe into the fluvial contribution to marine sediments in the South China Sea and consequently the related evolution of the East Asian summer monsoon (EASM) [14], whereas similar work on discussing the eolian dust input to marine sediments driven by the EAWM is still absent.

With the similar latitude and dominant monsoon system (i.e. the East Asian monsoon) to the South China Sea [4], adding its remoteness to the Asian continent and then weaker contribution from fluvial matter than the latter, the WPS should also be an ideal location for studying the evolution history of eolian dust input to marine sediments as well as its response to both aridity of the continental source regions and the EAWM intensity $[9,10]$. As to core MD063047 sediments, loads of typical components (i.e. $\mathrm{Al}_{2} \mathrm{O}_{3}$ and $\left.\mathrm{K}_{2} \mathrm{O}\right)$ of the eolian dust factor $(\mathrm{F} 2)$ are both positive, so an increase or decrease of F2 score should mean an increase or decrease of the eolian dust contribution to the study sediments, and thus enhancement or weakening of aridity in the continental source areas and intensity of the EAWM. From Figure 5, we can easily find the obviously glacial-interglacial periodicity of the eolian dust factor score of core MD06-3047 sediments, which is perfectly matched with

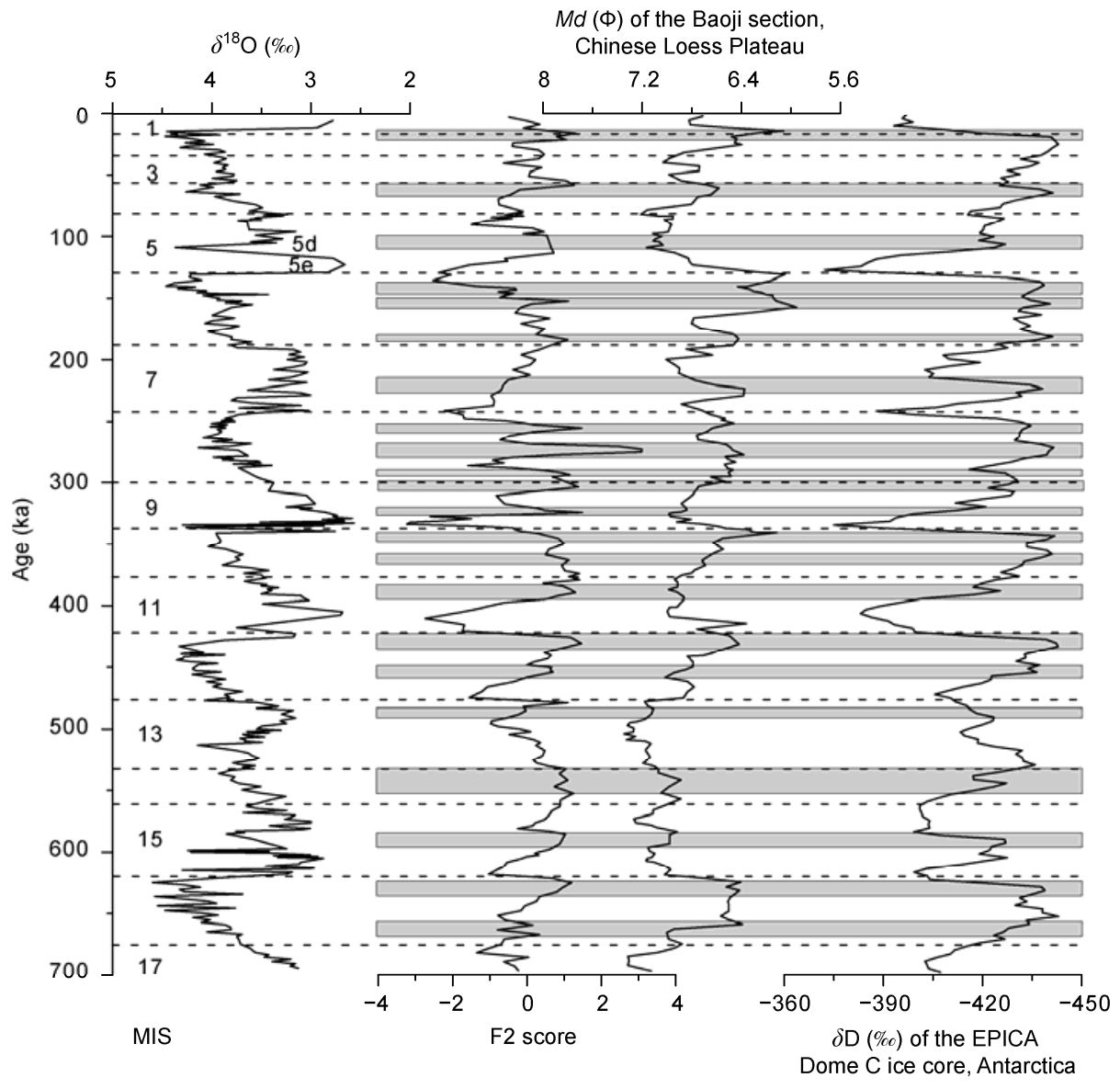

Figure 5 Comparison of the eolian dust factor score of core MD06-3047 sediments with oxygen isotopes of benthic foraminifera of the same core, medium grain size $(M d)$ of the Baoji section, Chinese Loess Plateau [34], and $\delta \mathrm{D}$ of the EPICA Dome C ice core, Antarctica [35]. 
that recorded by oxygen isotopes of the benthic foraminifera tests. The eolian dust contribution to the study sediments increased during glacial periods, indicating temporally colder weather and enhanced aridity in the continental source regions of eolian dust as well as strengthened intensity of the EAWM. In contrast, warmer and wetter conditions in the continental source areas of atmospheric dust, together with temporally weakened EAWM intensity, led to less eolian dust input to the WPS sediments during interglacial periods. We thus conclude that the evolution of the EAWM was controlled by the glacial-interglacial cycles.

Chinese loess, deep-sea sediment, and polar ice core have been globally accepted as three backbones for paleoenvironmental research [5-7,34-36]. The Chinese loess sequences are characterized by fine grain size, high sedimentation rate, and good continuity, and thus one of the best continental recorders of paleoenvironmental evolution during the late Cenozoic. Polar ice cores can provide the most direct and high time resolution record of atmospheric change in the late Quaternary. To further validate the creditability of the eolian dust factor score got in the present study for indicating the EAWM evolution, we compared our results with $M d$ value of the Baoji section, Chinese Loess Plateau, and $\delta \mathrm{D}$ value of the EPICA Dome C ice core, Antarctica (Figure 5). Lower Md value of the Baoji loess sequence indicates coarser grain size and then stronger EAWM intensity, while lower $\delta \mathrm{D}$ value of the EPICA Dome $\mathrm{C}$ ice core corresponds to drier and colder weather. Comparison results clear show the good coherence of their change trends, all characterized by the obviously glacialinterglacial periodicity (Figure 5). In the nearby South China Sea, the periodic fluctuation of the terrestrial factor score since $\sim 600 \mathrm{ka}$ also indicated that the glacial-intergla- cial cycles have been the main force driving the evolution of the EASM [14]. Besides, the EAWM intensity has been obviously strengthened since $600 \mathrm{ka}$, which is reflected by the higher eolian dust factor scores during glacial periods after MIS 14 than those of MIS 16 in the study core (Figure 5). Similarly, the MAR values of eolian dust both in the North Pacific and the Chinese Loess Plateau over the last $600 \mathrm{ka}$ are the highest in the late Cenozoic $[5,36]$, suggesting that the arid environment in the Asian continent as well as the enhanced EAWM had formed before $600 \mathrm{ka}$. Notably, almost each peak of these different indices can be well compared, as indicated by the shadow areas in Figure 5, such as the co-appearance of higher $\mathrm{F} 2$ score, heavier $\delta^{18} \mathrm{O}$ ratio, and lower $\delta \mathrm{D}$ value in the middle of MIS 5 period ( MIS $5 \mathrm{~d})$ as well as the corresponding of three peaks of them in MIS 8 stage. The discussion mentioned above all prove the validity of the eolian dust factor score here for studying the EAWM evolution and aridity in the continental source regions of atmospheric dust, which might shed light on solving some key problems appeared during the previous scientific researches in the nearby areas (e.g. whether the formation mechanism of diatom mats found in the EPS is closely cor- related with the eolian dust input from the Asian continent). However, there are still some differences among our eolian dust factor score and other proxies including benthic $\delta^{18} \mathrm{O}$ curve, $M d$ value of the Chinese loess sequence, and $\delta \mathrm{D}$ value of the Antarctic ice core (Figure 5), possibly because of their different sample resolution and local control factors. In fact, more differences among variations of these indices are found in MIS 1 (four samples), MIS 2 (six samples), and MIS 4 (four samples) periods with lower time resolution in the study core (Figure 5).

\section{Conclusions}

Based on the comprehensive researches of composition, elemental occurrence phase, and R-mode factor analysis for major elements, together with typical element ratio and PAAS-normalized REE pattern, of core MD06-3047 sediments, their significance for sediment provenance and paleoenvironmental record in the WPS over the last $700 \mathrm{ka}$ were examined. The main conclusions we have drawn are summarized as follows:

(1) Nearby volcanic matter and eolian dust from the Asian continent are two dominant provenance end-members of the study samples.

(2) R-mode factor analysis results indicate that two main major-element groups $\mathrm{F} 1\left(\mathrm{TFe}_{2} \mathrm{O}_{3}, \mathrm{MgO}\right.$, and $\left.\mathrm{TiO}_{2}\right)$ and $\mathrm{F} 2$ $\left(\mathrm{Al}_{2} \mathrm{O}_{3}\right.$ and $\left.\mathrm{K}_{2} \mathrm{O}\right)$ are representative of a volcanic factor and an eolian dust factor, respectively. As to the left two major-element groups, including $\mathrm{F} 3\left(\mathrm{Na}_{2} \mathrm{O}\right.$ and $\left.\mathrm{P}_{2} \mathrm{O}_{5}\right)$ and $\mathrm{F} 4$ $(\mathrm{MnO})$, correspond to two minor factors affected by nearby volcanic action, biologic effect, and hydrothermal activity.

(3) The variation in the eolian dust factor score is characterized by the obviously glacial-interglacial periodicity, reflecting the change in the contribution of eolian dust to the study sediments and then recovering the evolution processes of aridity in the continental source regions of atmospheric dust and the EAWM intensity. Good comparison of the present work with oxygen isotopes of benthic foraminifera of the same core, grain size of the Baoji section, Chinese Loess Plateau, and $\delta \mathrm{D}$ of the EPICA Dome $\mathrm{C}$ ice core, Antarctica further has proved the validity of the eolian dust factor score as a new proxy for studying the eolian input into the WPS as well as its driving mechanism.

The authors would like to thank the scientific party and crew of the $R / V$ Marion Dufresne of the French Polar Institute for sampling. We are grateful to MA GengTian of the CL, IGGE, CAGS and WANG HongLi of the KLMGE, IO, CAS for their assistance in sample analysis. The anonymous reviewers and Dr. WAN ShiMing are appreciated for improving the English of the manuscript and offering constructive comments. This work was supported by the Public Science and Technology Research Funds Projects of Ocean, State Oceanic Administration of the People's Republic of China (201005003), the Open Fund of the KLMGE, IO, CAS, the National Natural Science Foundation of China (41106043 and 41230959), the National Basic Research Program of China (2007CB815903), and the Innovative Program of the Chinese Academy of Sciences (KZCX2-YW-221). 
1 Shi X F, Chen L R. Late Quaternary sedimentary geochemical characteristics of the West Philippine Sea (in Chinese). Oceanol Limnol Sin, 1995, 26: 124-131

2 Asahara Y, Tanaka T, Kamioka H, et al. Asian continental nature of ${ }^{87} \mathrm{Sr} /{ }^{86} \mathrm{Sr}$ ratios in north central Pacific sediments. Earth Planet Sci Lett, 1995, 133: 105-116

3 Clift P D, Plumb R A. The Asian Monsoon: Causes, History and Effects. Cambridge: Cambridge University Press, 2008

4 Liu T H, Tsai F, Hsu S C, et al. Southeastward transport of Asian dust: source, transport and its contributions to Taiwan. Atmos Environ, 2009, 43: 458-467

5 Rea D K, Snoeckx H, Joseph L H. Late Cenozoic eolian deposition in the North Pacific: Asian drying, Tibetan uplift, and cooling of the northern hemisphere. Paleoceanography, 1998, 15: 215-224

6 Patterson D B, Farley K A, Norman M D. ${ }^{4} \mathrm{He}$ as a tracer of continental dust: A 1.9 million year record of aeolian flux to the west equatorial Pacific Ocean. Geochim Cosmochim Acta, 1999, 63: 615-625

7 Guo Z T, Ruddiman W F, Hao Q Z, et al. Onset of Asian desertification by 22 Myr ago inferred from loess deposits in China. Nature, 2002, 416: 159-163

8 Wang P X, Clemens S, Beaufort L, et al. Evolution and variability of the Asian monsoon system: State of the art and outstanding issues. Quat Sci Rev, 2005, 24: 595-629

$9 \mathrm{Xu} \mathrm{Z} \mathrm{K,} \mathrm{Li} \mathrm{A} \mathrm{C,} \mathrm{Jiang} \mathrm{F} \mathrm{Q,} \mathrm{et} \mathrm{al.} \mathrm{Geochemical} \mathrm{character} \mathrm{and} \mathrm{material}$ source of sediments in the eastern Philippine Sea. Chin Sci Bull, 2008, 53: 923-931

10 Wan S M, Yu Z J, Clift P D, et al. History of Asian eolian input to the West Philippine Sea over the last one million years. Palaeogeogr Palaeoclimatol Palaeoecol, 2012, 326-328: 152-159

11 Dai L, Weng C Y. A survey on pollen dispersal in the western Pacific Ocean and its paleoclimatological significance as a proxy for variation of the Asian winter monsoon. Sci China Earth Sci, 2011, 54: 249-258

$12 \mathrm{Xu} \mathrm{Z} \mathrm{K,} \mathrm{Li} \mathrm{A} \mathrm{C,} \mathrm{Xu} \mathrm{F} \mathrm{J,} \mathrm{et} \mathrm{al.} \mathrm{Elemental} \mathrm{occurrence} \mathrm{phases} \mathrm{of} \mathrm{surface}$ sediments from the East Philippine Sea (in Chinese). Mar Geol Quat Geol, 2007, 27: 51-58

13 Shu Z H, Yang S Y, Dou Y G, et al. Geochemical compositions and paleoenvironmental implication of the residual fractions of Core DGKS9604 sediments in the Middle Okinawa Trough (in Chinese). Trop Geogr, 2009, 29: 236-240, 273

14 Meng X W, Xia P, Zhang J, et al. Evolution of the East Asian monsoon and its response to uplift of the Tibetan Plateau since 1.8 Ma recorded by major elements in sediments of the South China Sea. Chin Sci Bull, 2011, 56: 547-551

$15 \mathrm{Xu} \mathrm{Z} \mathrm{K,} \mathrm{Li} \mathrm{A} \mathrm{C,} \mathrm{Li} \mathrm{T} \mathrm{G,} \mathrm{et} \mathrm{al.} \mathrm{Major} \mathrm{element} \mathrm{compositions} \mathrm{of} \mathrm{surface}$ sediments in the East Philippine Sea and its geological implication (in Chinese). Mar Geol Quat Geol, 2010, 30: 43-48

16 Sun H J, Li T G, Sun R T, et al. Calcareous nannofossil bioevents and microtektite stratigraphy in the Western Philippine Sea during the Quaternary. Chin Sci Bull, 2011, 56: 2732-2738

17 Lisiecki L E, Raymo M E. A Pliocene-Pleistocene stack of 57 globally distributed benthic $\delta^{18} \mathrm{O}$ records. Paleoceanography, 2005, 20: PA1003

18 Thompson P R, Be A W H, Duplessy J-C, et al. Disappearance of pink-pigmented Globigerina ruber at $120000 \mathrm{yr} \mathrm{BP}$ in the Indian and Pacific Oceans. Nature, 1979, 280: 554-558
19 Taylor S R, McLennan S H. The Continental Crust: Its Composition and Evolution. Oxford: Blackwell, 1985

20 Wood D A, Mattey D P, Joron J L, et al. A geochemical study of 17 selected samples from basement cores recovered at sites 447, 448, 449, 450, and 451, Deep Sea Drilling Project Leg 59. In: Kroenke L, Scott R B, Balshaw K, et al., eds. Initial Reports of the Deep Sea Drilling Project 59. U.S. Govt. Printing Office, 1981. 743-752

21 Castillo P R, Newhall C G. Geochemical Constraints on Possible Subduction Components in Lavas of Mayon and Taal Volcanoes, Southern Luzon, Philippines. J Petrol, 2004, 45: 1089-1108

22 Marini J C, Chauvel C, Maury R C. Hf isotope compositions of northern Luzon arc lavas suggest involvement of pelagic sediments in their source. Contrib Mineral Petrol, 2005, 149: 216-232

23 Wen Q Z, Diao G Y, Geng A S, et al. Geochemistry of China Loess (in Chinese). Beijing: Geological Publishing House, 1989. 36-114

24 Gallet S, Jahn B M, Torii M. Geochemical characterization of the Luochuan loess-paleosol sequence, China, and paleoclimatic implications. Chem Geol, 1996, 133: 67-88

25 Bischoff J L, Heath G R, Leinen M. Geochemistry of deep-sea sediments from the Pacific manganese nodule province: DOMES sites A, B, C. In: Bischoff J L, Piper D Z, eds. Marine Geology and Oceanography of the Pacific Manganese Nodule Province. New York: Plenum Press, 1979. 397-436

26 Cha H J, Choi M S, Lee C B, et al. Geochemistry of surface sediments in the southwestern East/Japan Sea. J Asian Earth Sci, 2007, 29: 685-697

27 Shigemitsu M, Narita H, Watanabe Y W, et al. Ba, Si, U, Al, Sc, La, $\mathrm{Th}, \mathrm{C}$ and ${ }^{13} \mathrm{C} /{ }^{12} \mathrm{C}$ in a sediment core in the western subarctic Pacific as proxies of past biological production. Mar Chem, 2007, 106: 442455

28 Faure E. Principles of Isotope Geology. New York: Wiley, 1986. $141-153$

29 Duce R A, Liss P S, Merrill J T, et al. The atmospheric input of trace species to the world ocean. Global Biogeochem Cy, 1991, 5: 193259

30 Shi X F, Chen L R, Li K Y, et al. Study on minerageny of the clay sediment in the west of Philippine Sea (in Chinese). Mar Geol Quat Geol, 1995, 15: 61-72

31 Ge S L, Shi X F, Yang G, et al. Rock magnetic response to climatic changes in west Philippine Sea for the last $780 \mathrm{ka}$ : Discussion based on relative paleointensity assisted chronology. Front Earth Sci China, 2008, 2: 314-326

32 Liu Z F, Zhao Y L, Colin C, et al. Chemical weathering in Luzon, Philippines from clay mineralogy and major-element geochemistry of river sediments. Appl Geochem, 2009, 24: 2195-2205

33 Wei G J, Li X H, Liu Y, et al. Transfer patterns of Mn, Cd and Mo in sediments during early diagenesis: Evidences from sediment cores at ODP Site 1148 (in Chinese). Geochimica, 2005, 34: 129-135

34 Ding Z L, Derbyshire E, Yang S L, et al. Stacked 2.6-Ma grain size record from the Chinese loess based on five sections and correlation with the deep-sea $\delta^{18} \mathrm{O}$ record. Paleoceanography, 2002, 17, doi: 10.1029/2001PA000725

35 EPICA community members. Eight glacial cycles from an Antarctic ice core. Nature, 2004, 429: 623-628

36 Sun Y B, An Z S. History and variability of Asian interior aridity recorded by eolian flux in the Chinese Loess Plateau during the past 7 Ma. Sci China Ser D-Earth Sci, 2002, 45: 420-429

Open Access This article is distributed under the terms of the Creative Commons Attribution License which permits any use, distribution, and reproduction in any medium, provided the original author(s) and source are credited. 